\title{
Increasing use of the emergency department in a Swiss hospital: observational study based on measures of the severity of cases
}

Brigitte Santos-Eggimann

Institute of Social

and Preventive

Medicine,

University of

Lausanne, CH-1005

Lausanne,

Switzerland

Brigitte

Santos-Eggimann

assistant professor,

head of health services

research unit

Correspondence to: B Santos-Eggimann Brigitte.Santos-

Eggimann@inst.

hospvd.ch

BMJ 2002;324:1186-7
In many countries the number of consultations in hospital emergency departments increased over the past decade. Possible explanations are the ageing of the population, increased levels of social deprivation, higher expectations from urban populations, or artefacts in admissions data. ${ }^{1-3}$ Implications for healthcare planners are far reaching; an understanding of how much of this trend is attributable to an increase in less severe cases is crucial. ${ }^{4}$ Studies of administrative data may aid such understanding.

\section{Methods and results}

I analysed administrative data collected from 1993 to 1999 for consultations in the emergency department of the Centre Hospitalier Universitaire Vaudois, the public general hospital serving 286000 inhabitants in the Lausanne area. Over this period, the number of consultations increased by 7421 from 30822 to 38 243. This was a mean annual increase of $1.5 \%$ between 1993 and 1996 and 5.9\% between 1996 and 1999 while the resident population remained stable (it increased by only $0.5 \%$ ).

The three measures of the severity of emergencies that I used were the proportion of patients that $(a)$ was transported by ambulance or helicopter; $(b)$ stayed in the emergency department for at least six hours (not attributable to understaffing in this setting); and ( $c$ ) died or were transferred to another acute care department. From 1998 the triage nurse assigned a National Advisory Committee for Aeronautics admission category. ${ }^{5}$ The proportion to which at least one measure of severity applied increased steadily with age ( $17 \%$ of children younger than 10 years old and $86 \%$ of people aged 80 years and older). Although the number of consultations grew, the proportion to which at least one of the three measures of severity applied remained stable; it ranged from $44.3 \%$ to $46.1 \%$ (table).
Further analysis suggested two explanations for the stability of the proportion of consultations to which a measure of severity applied. The number of consultations with people 80 years and older more than doubled between 1993 and 1999 (1603 v 3510), and proportionately more measures of severity applied.

On the other hand, there was an increase of 3471 (55\%) consultations with patients of "other nationalities," to which fewer measures of severity applied. Foreign nationals with a long tradition of migration to Switzerland showed an increase similar to Swiss nationals. The "other nationalities" subgroup is nationalities other than Swiss, French, German, Italian, or Spanish.

\section{Comment}

The increased use of the emergency department was not associated with a change in the proportion of severe cases being seen. More than 70\% $((3471+1907) /$ 7421) of the increase in emergency department use over the seven year period is accounted for by an ageing population and immigration.

The ageing of the population increased the number of consultations due to immediate medical needs. Also, the changing structure of younger age groups due to immigration led to increased demand that could be treated in settings other than the emergency department. The different social and cultural backgrounds of recent immigrants may explain the difficulty in diverting less severe cases away from emergency departments. Hospital emergency departments have to be able to respond to this demand.

Contributors: BS-E is the sole author of this paper.

Funding: Health Services Research Unit of the Institute of Social and Preventive Medicine, University of Lausanne.

Competing interests: None declared.

1 Capewell S. The continuing rise in emergency admissions. BMJ 1996;312:991-2

Emergency consultations in which given measures of severity applied at Centre Hospitalier Universitaire Vaudois, Lausanne, Switzerland, 1993-9

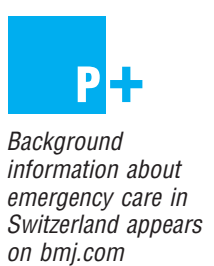

\begin{tabular}{|c|c|c|c|c|c|c|c|c|c|c|c|c|}
\hline \multirow[b]{3}{*}{ Year } & \multicolumn{12}{|c|}{ Measure of severity } \\
\hline & \multicolumn{3}{|c|}{ Length of stay $\geqslant 6$ hours } & \multicolumn{3}{|c|}{ Dead or hospitalised } & \multicolumn{3}{|c|}{ Ambulance or helicopter } & \multicolumn{3}{|c|}{ At least one criterion fulfilled } \\
\hline & $\mathbf{N}$ & n & $\%$ & $\mathbf{N}$ & $\mathrm{n}$ & $\%$ & $\mathrm{~N}$ & n & $\%$ & $\mathbf{N}$ & n & $\%$ \\
\hline 1993 & 30818 & 7766 & 25.20 & 30800 & 10149 & 32.95 & 29532 & 7066 & 23.93 & 30882 & 14199 & 46.07 \\
\hline 1994 & 31937 & 7717 & 24.16 & 31929 & 9842 & 30.82 & 31057 & 7416 & 23.88 & 31937 & 14255 & 44.63 \\
\hline 1995 & 33100 & 7812 & 23.60 & 32931 & 10153 & 30.83 & 32262 & 7453 & 23.10 & 33101 & 14732 & 44.51 \\
\hline 1996 & 32242 & 7574 & 23.49 & 32049 & 9798 & 30.57 & 30056 & 7153 & 23.80 & 32243 & 14308 & 44.38 \\
\hline 1997 & 34300 & 7887 & 22.99 & 34115 & 10176 & 29.83 & 32573 & 7891 & 24.23 & 34301 & 15326 & 44.68 \\
\hline 1998 & 36382 & 8622 & 23.70 & 36376 & 10666 & 29.32 & 34809 & 8410 & 24.16 & 36384 & 16155 & 44.40 \\
\hline 1999 & 38242 & 9325 & 24.38 & 38235 & 11137 & 29.13 & 36359 & 8874 & 24.29 & 38243 & 16950 & 44.32 \\
\hline
\end{tabular}

$\mathrm{N}=$ number of valid cases for analysis.

$\mathrm{n}=$ number of cases with measure of severity. 
2 Hull SA, Rees Jones I, Moser K. Factors influencing the attendance rate at accident and emergency departments in east London: the contribution of practice organization, population characteristics, and distance. J Health Serv Res Policy 1997;2:6-13.

3 Morgan K, Prothero D, Frankel S. The rise in emergency admissions: crisis or artefact? Temporal analysis of health services data. BMJ $1999 ; 319: 158-9$
4 Meggs MJ, Czaplijski T, Benson T. Trends in emergency department utilization: 1988-1997. Acad Emerg Med 1999;6:1030-5

5 Tryba M, Brüggemann H, Echtenmeyer U. Klassifizierung von Erkrankungen und Verletzungen in Notarztrettungssystemen: National Advisory Committee for Aeronautics (NACA). Anasthesiol Intensizmed Notfallmed Schmerzther 1980;6:725-7.

(Accepted 22 October 2001)

\title{
Prescribing incentive schemes in two NHS regions: cross sectional survey
}

\author{
Mark Ashworth, Stacey Golding, Lindsey Shephard, Azeem Majeed
}

The introduction of fundholding in primary care in the United Kingdom contained prescribing costs, although the effect was modest and seemingly not accompanied by parallel improvements in the quality of prescribing. With the advent of primary care groups in 1999 a new incentive scheme was devised to influence prescribing. Financial rewards to general practices could be linked more explicitly to improvements in the quality and appropriateness of prescribing than under fundholding schemes. The money had to be invested in improvements to services available to patients. ${ }^{2}$ We surveyed prescribing indicators and financial rewards associated with such schemes in two NHS regions in England.

\section{Methods and results}

In 2000 we sent two questionnaires to the prescribing adviser of each primary care group in the 66 London and 79 South East regional offices of the NHS Executive. One hundred and twenty one $(83 \%)$ responded with details about their incentive scheme, and 129 $(89 \%)$ provided financial information on prescribing.

The table shows the categories of indicator most often included in the schemes. Quality based indicators were reported by $83 \%$ (100) and cost based indicators by $78 \%$ (94) of primary care groups. Some categories were used to indicate both quality and cost. Sixty three per cent of schemes (76) required the collection of data not based on prescribing analysis and cost (PACT), such as data from prescribing audits or reviews of repeat prescribing.

Prescribing costs ranged from an underspend of $7 \%$ to an overspend of $14 \%$ (median $4.5 \%$ overspend). Eleven $(9 \%)$ primary care groups made no incentive payment to any practice, whereas 29 (22\%) groups made some payment to every practice. Primary care groups offering rewards to a higher proportion of practices were as likely to have overspent their prescribing budget as those offering rewards to fewer practices (Spearman's correlation coefficient -0.15 , $\mathrm{P}=0.10)$. Altogether $66(61 \%$ of the 109 primary care groups that responded to this question) of primary care groups gave a reward only if practices had also achieved one or more of the quality indicators in their incentive scheme. The size of reward varied: $40(70 \%$ of the 57 primary care groups that responded to this question) restricted the maximum payment to $£ 3000$ $(€ 4900)$ or less, five made payments exceeding $£ 10000$, and two made payments exceeding $£ 20000$ per practice. Although 22\% of primary care groups had declared that up to $£ 45000$ per practice was avail- able under the scheme, just two made payments of this magnitude. We did not find a significant relation between the size of reward offered or received and the prescribing overspend of the primary care group.

\section{Comment}

The lack of an association of the incentives with prescribing overspends in primary care groups implies an inefficient system, in which large rewards are not clearly connected with either cost or quality based prescribing achievements. Prescribing incentive schemes in primary care are characterised by a wide range of prescribing indicators and an emphasis on improving the quality and controlling the costs of prescribing. Over half of the groups included non-PACT based indicators, which generally favour quality improvement since PACT data alone tend to be more useful in controlling costs. ${ }^{3}$ Further evidence that quality improvement was important came from those groups that withheld financial rewards to underspending practices unless quality criteria were also achieved. In a national tracker survey of 77 primary care groups a similar spread of prescribing indicators was noted, with an emphasis on quality (the results of financial aspects of the prescribing incentive scheme have not yet been

Categories of prescribing indicators used by primary care groups in two NHS regions in their prescribing incentive schemes

\begin{tabular}{ll}
$\begin{array}{l}\text { Prescribing indicator } \\
\text { Quality }\end{array}$ & $\begin{array}{c}\text { (95\% } \mathbf{C I}) \text { of primary care } \\
\text { groups ( } \mathbf{n}=\mathbf{1 2 1})\end{array}$ \\
\hline Antibiotics & 73 (66 to 82$)$ \\
\hline Cardiovascular drugs & $31(22$ to 39$)$ \\
\hline Gastrointestinal drugs & $23(15$ to 30$)$ \\
\hline Non-steroidal anti-inflammatories & $22(14$ to 29$)$ \\
\hline Benzodiazepines & $17(10$ to 24$)$ \\
\hline Asthma drugs & $16(9$ to 22$)$ \\
\hline Antidepressants & $3(0.1$ to 7$)$ \\
\hline Diabetes drugs & $3(0.1$ to 7$)$ \\
\hline Osteoporosis prophylaxis & $3(0.1$ to 7$)$ \\
\hline Cost & $88(82$ to 94$)$ \\
\hline Generic prescribing & $59(50$ to 68$)$ \\
\hline Gastrointestinal drugs & $24(17$ to 32$)$ \\
\hline Non-steroidal anti-inflammatories & $18(11$ to 25$)$ \\
\hline Modified release preparations & $13(7$ to 20$)$ \\
\hline Drugs of limited clinical effectiveness & $12(6$ to 18$)$ \\
\hline Antibiotics & $7(2$ to 11$)$ \\
\hline Combination products & $5(1$ to 9$)$ \\
\hline Emollients & $3(0$ to 5$)$ \\
\hline Cardiovascular drugs & $2(0$ to 4$)$ \\
\hline Antidepressants & $1(0$ to 2$)$ \\
\hline Antipsychotic drugs &
\end{tabular}

Guy's, King's College, and St Thomas's School of Medicine, Department of General Practice and Primary Care, London SE11 6SP

Mark Ashworth STaRNet lead general practitioner Lindsey Shephard research nurse

North Lambeth Primary Care Group, London SE1 8RG Stacey Golding prescribing adviser

School of Public Policy, University College London, London WC1H 9EZ Azeem Majeed senior lecturer in general practice Correspondence to: M Ashworth mark.ashworth@ kcl.ac.uk

\section{BMJ 2002;324:1187-8}

